\title{
BMJ Open Adverse Drug reactions in an Ageing PopulaTion (ADAPT) study protocol: a cross-sectional and prospective cohort study of hospital admissions related to adverse drug reactions in older patients
}

Caitriona Cahir, ${ }^{1}$ Carmel Curran, ${ }^{2}$ Catherine Byrne,${ }^{1}$ Caroline Walsh, ${ }^{1}$ Anne Hickey, ${ }^{1}$ David J Williams, ${ }^{2}$ Kathleen Bennett ${ }^{1}$

To cite: Cahir C, Curran C, Byrne C, et al. Adverse Drug reactions in an Ageing PopulaTion (ADAPT) study protocol: a cross-sectional and prospective cohort study of hospital admissions related to adverse drug reactions in older patients. BMJ Open 2017;7:e017322. doi:10.1136/ bmjopen-2017-017322

- Prepublication history for this paper is available online. To view these files, please visit the journal online (http://dx.doi org/10.1136/bmjopen-2017017322).

Received 14 April 2017 Revised 14 April 2017 Accepted 2 May 2017

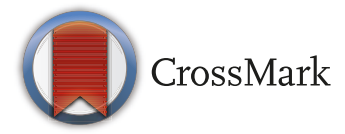

${ }^{1}$ Division of Population Health Sciences, Royal College of Surgeons in Ireland, Dublin, Ireland

${ }^{2}$ Department of Geriatric and Stroke Medicine, Royal College of Surgeons in Ireland and Beaumont Hospital, Dublin, Ireland

Correspondence to Ms Caitriona Cahir; caitrionacahir@rcsi.ie

\section{ABSTRACT}

Introduction Older people experience greater morbidity with a corresponding increase in medication use resulting in a potentially higher risk of adverse drug reactions (ADRs). The aim of this study is to determine the prevalence and characteristics of ADR-related hospital admissions among older patients ( $\geq 65$ years) and their associated health and cost outcomes.

Methods and analysis The proposed study will include a cross-sectional study of ADR prevalence in all patients aged $\geq 65$ years admitted acutely to a large tertiary referral hospital in Ireland over a 9-month period (2016-2017) and a prospective cohort study of patient-reported health outcomes and costs associated with ADR-related hospital admissions. All acute medical admissions will be screened for a suspected ADR-related hospital admission. A number of validated algorithms will be applied to assess the type, causative medications, preventability and severity of each ADR. ADRs will be determined, using a consensus method, by an expert panel. Patients who provide consent will be followed up 3 months post-discharge to establish patientreported health outcomes (health service use, healthrelated quality of life, adherence) and costs associated with ADR-related hospital admissions. A random sample of patients admitted to hospital without a suspected ADR will be invited to take part in the study as a control group. Ethics and dissemination Ethical approval was obtained from Beaumont Hospital Ethics Committee. Findings will be disseminated through presentations and peer-reviewed publications.

\section{INTRODUCTION}

An adverse drug reaction (ADR) has been defined as 'an appreciably harmful or unpleasant reaction resulting from an intervention relating to the use of a medicinal product'. ${ }^{1}$ ADRs are common and result in significant morbidity, mortality and increased healthcare costs. ${ }^{2}$ Studies in general adult populations have indicated that $5 \%-7 \%$ of all hospitalisations are due to ADRs, with over half of these judged to be preventable, and
Strengths and limitations of this study

- This study will provide detailed information on the prevalence and characterisation of adverse drug reactions (ADRs) in a large older population

- There have been no long-term follow-up studies of older patients with ADR-related hospital admissions and a range of risk factors, health outcomes and costs will be assessed

- ADR determination in older populations is challenging and there is a risk of misclassification; a multifaceted review of each suspected ADR will be undertaken as well as independent review by an expert panel

- A number of patients may not have the capacity to complete the health outcome measures

that $3 \%-6 \%$ of ADRs are fatal or have serious health consequences. ${ }^{3-5}$ Healthcare costs attributable to ADRs have been estimated to be $5 \%-9 \%$ of total inpatient costs per annum. ${ }^{6}$ Older people experience greater morbidity with a corresponding increase in medication utilisation resulting in a higher risk of ADRs. ${ }^{7}$ Ageing is also associated with a variety of physiological changes affecting the pharmacokinetics and pharmacodynamics of medications, which may increase the potential for drug toxicity and ADRs. ${ }^{8}$ Therefore, older people are potentially at an increased risk of ADR-related hospital admissions and many of these ADRs may be preventable. ${ }^{9}$ Studies have indicated that more than half of hospital admissions for ADRs are preventable with only $19 \%-28 \%$ of ADRs causing hospital admission in older patients considered unavoidable. ${ }^{49}$

Two systematic reviews of international studies have suggested a median ADR-related hospital admission rate of $10 \%$ and $11 \%$, 
respectively, in those aged $\geq 65$ years..$^{10}$ One of these systematic reviews reported a wide variation in the overall ADR prevalence rate between studies ranging from $5.8 \%$ in 1756 older Italian patients to $46.3 \%$ in a smaller Belgian study. ${ }^{911} 12$ This wide variation in reported prevalence rates may be due, in part, to different admission settings (geriatric unit versus accident and emergency (A\&E) ) and differences in study methods used to define and identify ADRs. ${ }^{13}$ Differences in prescribing practices and available medications across regions may also contribute to this wide variation. ${ }^{14}$ In Ireland, studies to date have included relatively small numbers of patients and were conducted over short time periods. ${ }^{15} 16$

ADRs are difficult to identify in older populations and patients often present acutely with symptoms that are highly prevalent in people with multiple comorbidities, for example, dizziness, delirium or falls. ${ }^{13}$ Current hospital reporting systems significantly under-report the incidence of ADRs and provide unreliable estimates of ADR-related hospital admissions in older populations. ${ }^{17} 18$ A systematic review found a median ADR under-reporting rate of $94 \%$ across 39 studies. ${ }^{19}$ To accurately detect ADRs, a number of methods are required including an in-depth medical record review and a causality assessment between the drug and the adverse clinical event. ${ }^{20}$

Several factors have been reported to contribute to the increased incidence of ADRs in older populations. These include increasing age, polypharmacy, multimorbidity, prior ADR and dementia in the acute setting. ${ }^{11} 21$ There is some evidence that potentially inappropriate prescribing, identified by the STOPP tool, is associated with an increased risk of ADRs and hospitalisation in older people. ${ }^{2223}$ Errors in medication administration and autonomous modification of medication schedules have also been reported to contribute to ADRs. ${ }^{24}$ However, predictive risk factors for ADRs in older populations are still poorly understood. Current validated risk prediction tools have focused mainly on ADRs occurring in the hospital setting and do not include a comprehensive list of risk factors, such as functional and social factors, which may contribute to ADR-related hospitalisation. ${ }^{25} 26$

Few studies have investigated patient outcomes and costs associated with ADR-related hospital admissions. There is some evidence that ADRs related to hospital admissions are associated with higher subsequent health services utilisation and costs. ${ }^{27}$ Previous studies have found that those presenting with an ADR have a longer median hospital stay and a higher rate of subsequent outpatient health service use than those without ADRs. ${ }^{2728}$ A study in Canada found that hospital admissions due to ADRs in older patients cost an estimated US $\$ 35.7$ million annually. ${ }^{29}$ Few studies have examined the physical and psychological morbidity associated with ADRs in older populations, as well as the cost of ADRs and subsequent medication management.

Given the limited number of prospective studies of ADR-related hospital admissions in older populations, there is a need to establish the prevalence of ADRs in older people and to obtain a greater understanding of the risk factors, health outcomes and costs associated with ADR-related admissions. This will inform the development of policies and interventions focused on improving medication management in older people and identify where resources can be most effectively used to reduce older peoples' risk of ADRs and associated morbidity and costs.

\section{Aims and objectives}

The aim of this study is to determine the prevalence and characteristics of ADR-related hospital admissions among older patients ( $\geq 65$ years) and their associated health and cost outcomes. The specific objectives are:

- To determine the prevalence of ADR-related hospital admissions among older patients ( $\geq 65$ years)

- To examine the type and range of drug classes involved in ADR-related hospital admissions

- To determine the causality, preventability and severity of each ADR

- To identify the risk factors associated with ADRrelated hospital admissions

- To examine patient discharge outcomes and the length of hospital stay of ADR-related hospital admissions

- To establish patient-reported health outcomes associated with ADR-related hospital admissions (health service use, health-related quality of life (HRQOL) and medication adherence)

- To establish the associated costs of ADR-related hospital admissions

\section{METHODS}

\section{Study design}

The proposed study will include a cross-sectional study of ADR prevalence in all patients aged $\geq 65$ years admitted acutely to a large tertiary referral hospital in Ireland over a 9-month period (2016-2017) and a prospective cohort study of patient-reported health outcomes and costs associated with ADR-related hospital admissions.

\section{Observation period}

The study recruitment period is from 27 November 2016 to 27 August 2017. A sample of ADR and non-ADR patients who provide informed consent will be followed up 3 months post-discharge from hospital to establish patient-reported health outcomes and costs associated with ADR-related hospital admissions.

\section{ADR screening}

A cross-sectional study of all acute admissions through the Emergency Department, Outpatients Department, and direct acute admissions to the hospital wards will be undertaken. All admitted patients will be screened for a suspected ADR-related hospital admission within the first 36 hours of admission by the research team (Specialist Registrar in Geriatric Registrar (CCu), two hospital pharmacists (CW and $\mathrm{CB})$ ) using a previously validated 
screening process. ${ }^{40}$ An acute admission is defined as the acceptance of the care of a patient for admission to an acute bed within the hospital under a named treating clinician or surgeon. Patients transferred from other hospitals will be excluded.

An ADR is defined as 'an appreciably harmful or unpleasant reaction, resulting from an intervention related to the use of a medicinal product, which predicts hazard from future administration and warrants prevention or specific treatment, or alteration of the dosage regimen, or withdrawal of the product.' ${ }^{1}$ The screening approach incorporates a multifaceted review by the research team of each admitted patient to assess the likelihood of an ADR being a reason for admission in the context of the patient's medication, clinical condition, medical history, comorbidities and investigation results. Where an ADR is suspected or where the medication history is unclear or incomplete, a full medication reconciliation will be completed. A number of independent sources will be consulted to verify the patient's medication history, including the patient's self-reported medication list, pharmacist medication list and general practitioner (GP) medication list. A current medication list will be established, including a list of all recently discontinued or short-course medications. Depending on the nature of the clinical presentation, further enquiry into the patient's past medication usage with their pharmacist and/or GP may be made, as some ADRs can present some time after discontinuation of the medication. Enquiry will also be made about the use of over-the-counter (OTC) medications and herbal preparations as part of the medication reconciliation process. Adherence to each medication will also be assessed by patient self-report and consolidation between patient self-report and pharmacist dispensing record will be undertaken, where possible.

The research team will electronically record details of the nature of the suspected ADR, suspected medications and relevant clinical information, comorbidities and investigation results required for suspected ADR determination. In cases where the admission diagnosis and the presence of an ADR is uncertain, the patient's clinical course and investigation results will be followed up by the research team until a diagnosis is made or the patient is discharged.

In order to determine whether the admission is due to an ADR, a reliable assessment of the relationship between drug administration and the adverse clinical event is required in terms of causality, preventability and severity. ${ }^{32}$ The research team will apply a number of decision aids and validated algorithms to assess the type, causative medication, preventability and severity of each ADR. The research team will categorise the suspected ADRs as either type A (dose dependent and predictable from the known pharmacology) or type B (idiosyncratic, no clear dose/response relationship and not predictable from the known pharmacology) according to the Rawlins and Thompson classification system. ${ }^{33}$ ADR causality will be determined by the research team applying the WHO criteria, Naranjo criteria and Liverpool Algorithm. ${ }^{34-36}$ The Hallas criteria will be used to categorise the avoidability/preventability of the ADRs as definitely avoidable, possibly avoidable or unavoidable. ${ }^{37}$ ADR severity will be classified as mild, moderate or severe using the Hartwig severity assessment scale. ${ }^{38}$ The research team will also assess if the ADR was due to a known drug interaction as outlined in the Summary of Product Characteristics (SmPC). The details of medications will be recorded using the WHO Anatomical Therapeutic Chemical (ATC) codes. The nature of the reaction will be reported using Medical Dictionary for Regulatory Activities terminology. ${ }^{35}$

\section{Participant recruitment}

All patients with a suspected ADR and admitted to hospital during the 9-month study recruitment period will be asked by the research team to take part in a prospective cohort study investigating medication management in older populations. Patients with a suspected ADR are eligible to take part in the prospective cohort study if they are aged $\geq 65$ years and English speaking. Patients will be asked by the research team to provide informed consent: (i) to complete a baseline questionnaire measuring their health service use, health-related quality of life (HRQOL) and medication adherence, prior to hospital admission; (ii) to be contacted 3 months post-discharge by the research team to complete a follow-up questionnaire including the same measures; and (iii) for the research team to link their prescription dispensing information per the Health Services Executive (HSE) Primary Care Reimbursement Services (PCRS) pharmacy claims database to the information they provided in their questionnaire and their hospital medical record (for General Medical Services (GMS) patients only). The GMS scheme is means tested and provides individuals with free or substantially subsidised healthcare and prescription medications. ${ }^{39}$ It is estimated that over $97 \%$ of those aged $\geq 70$ years nationally avail of the scheme. ${ }^{40}$ The HSE-PCRS pharmacy claims database provides details on monthly dispensed medications for each individual within the GMS scheme. Prescription medications are coded using the ATC classification system and strength, quantity, method and unit of administration of each drug dispensed are available. ${ }^{41}$

A random sample of patients, who are determined by the research team not to have a suspected ADR on screening and who are admitted to hospital during the 9-month study recruitment period, will also be invited to take part in the follow-up study. This cohort of nonADR patients will be asked to provide informed consent to complete the same questionnaire measures at baseline and follow-up as the ADR cohort, with linkage to their prescription dispensing information, as a comparison control group. Control patients are eligible to take part in the prospective cohort study if they are aged $\geq 65$ years, English speaking and prescribed at least one medication. Patients will be randomised to the control group from the hospital admission list, which details patients' 
chronological order of hospital admission on each day for those aged $\geq 65$ years, using randomisation software http://www.randomization.com. These randomised patients will be invited to take part in the study as control patients. If a control group patient is subsequently determined to have a suspected ADR, an additional patient will be randomised and invited to take part in the study instead. Patients with a suspected ADR and control patients are ineligible to take part in the prospective cohort study if they are $<65$ years, non-English speaking or terminally ill.

Screening of acute admissions for suspected ADRs and initial medication review may include unconscious patients, patients with intellectual, visual or hearing impairments or acquired brain injury. If the patient is deemed unable to provide informed consent due to illness severity or physical or cognitive impairment, the patient's next of kin will be asked to provide assent to take part in the study. Patients may be deemed temporarily unable to provide informed consent or permanently unable to provide informed consent (such as in the case of advanced dementia). The medical and nursing teams managing and providing the patient's care will be able to identify those patients who are incapable permanently of providing informed consent and will be able to provide the research team with an estimation regarding recovery and improvement for those temporarily unable to provide informed consent. For patients deemed permanently unable to provide informed consent, the patient's next of kin will be asked to give assent to provide the same information and answer an abbreviated questionnaire to the best of their ability, as described above for patients who are able to give informed consent. The selection of the study cohort is shown graphically in figure 1 .

\section{Sample size}

Approximately 3500 hospital admissions will be reviewed for a suspected ADR during the 9-month study period (2016-2017). It is estimated that 350 participants (approximately $10 \%$ of the 3500 hospital admissions) will have an ADR during the study period. This number provides an estimate of the prevalence of ADRs within $\pm 1 \%$ precision. A further 350 participants who are determined not to have an ADR (control group) will also be recruited to take part in the study. The 700 participants will be invited to complete a baseline and a follow-up questionnaire 3 months post-discharge. We anticipate a $50 \%$ response rate (approximately $\mathrm{n}=350$ participants; $175 \mathrm{ADR}$ cohort, 175 non-ADR cohort).

\section{Risk factors associated with ADRs}

Table 1 provides an overview of the measures to be collected as part of the ADR determination process and potential risk factors for ADRs. The potential risk factors for ADRs, based on previous systematic reviews, are categorised as: (i) medication-related risk factors; (ii) disease-related risk factors; (iii) functional ability-related risk factors; (iv) medication adherence-related risk factors; and (iv) patient-related risk factors. ${ }^{11}$ Medication-related risk factors include the types and number of medications that patients are prescribed, potentially inappropriate medication and drug/drug interactions. Potentially inappropriate prescribing will be assessed using the STOPP and START screening tools; STOPP consists of a set of inappropriate combinations of medicines and diseases that should be avoided or stopped and START is a set of recommended treatments for given conditions. ${ }^{42}$ Drug/drug interactions will be assessed per using SmPC documents. Disease-related risk factors include certain diagnoses, for example, impaired renal function and the patient's comorbidity burden. Patient comorbidity will be measured based on the patient's hospital record (Charlson comorbidity index).$^{43}$ Delirium will be assessed using the 4AT on hospital admission, a sensitive and specific screening tool for assessing delirium in older inpatients, including those with probable dementia. ${ }^{44}$

Functional ability-related risk factors include measures of frailty, falls and mobility. A recent systematic review of the diagnostic accuracy of instruments to identify frailty in older populations recommended the use of more than one test to identify frailty in routine care.$^{45}$ Frailty will be assessed at baseline on hospital admission using three different validated measures for all patients with a suspected ADR and control patients; the Triage Risk Screening Tool, ${ }^{46}$ PRISMA- $7{ }^{47}$ and FRAIL. ${ }^{48}$ Patients will be asked to self-report if they have fallen within the last year, their level of mobility (use of walking aids) and physical fitness, any unintentional weight loss in the previous 6 months and any problems in daily life due to poor vision and/or hearing. Medication adherence risk factors include medication adherence and medication management techniques. Adherence to each prescribed medication will be estimated at hospital admission for all patients with an ADR and control patients, by confirming patient self-reported medication list with the community pharmacy dispensing record, where possible. Patients will also be asked questions about their medication management including use of blister packs and pill organisers. Patient-related risk factors include age, gender, smoking status and alcohol usage. Patients' medical card (GMS) status (ie, access to free medical care based on means testing) will be recorded from patient's medical record and used as a proxy for socioeconomic status.

\section{Outcomes}

\section{Main outcome-ADRs}

The main outcome will be the prevalence and characterisation of ADRs in all patients aged $\geq 65$ years admitted acutely to a large tertiary referral hospital in Ireland. Suspected ADR-related hospital admissions, as determined by the research team, will be reviewed using a one round questionnaire consensus method by an expert panel consisting of a senior clinical pharmacist, a clinical pharmacologist and a consultant geriatrician. The panel will establish a suspected ADR as a 'true ADR' if the reason for hospital admission is consistent with the 


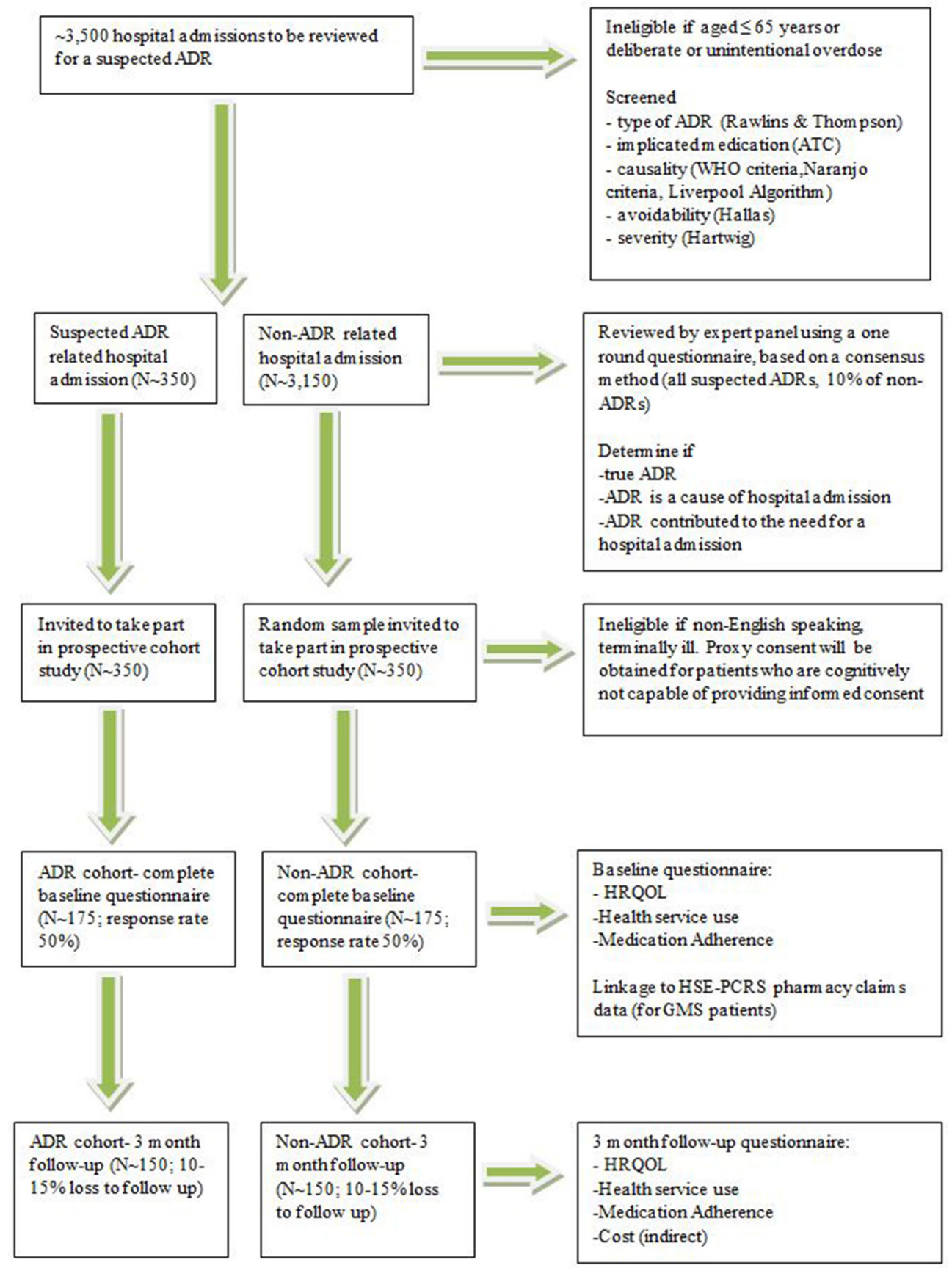

Figure 1 Description of study cohort. ADR, adverse drug reaction; GMS, General Medical Services; HRQOL, health-related quality of life; HSE-PCRS, Health Services Executive Primary Care Reimbursement Services.

known adverse effect profile of the drug (according to the SmPC), if there is a temporal relation with the start of drug therapy and if, after appropriate investigations, other causes are excluded as in previous ADR research studies. $^{4}$

Each member of the panel will independently review the information provided on the nature of the ADR, suspected medications, OTC medications, patient's clinical conditions, medical and prescription drug history and results of clinical and laboratory investigations (table 1). Each member of the panel will rate their confidence that: (i) the suspected ADR is a 'true ADR'; (ii) the ADR is a cause of hospital admission; and (iii) the ADR contributed to the need for hospital admission on a scale of 1 (definitely not) to 5 (definitely). For each suspected ADR, the median and IQR will be calculated for each scale and consensus will be defined as $\geq 4.0$ for each scale. ${ }^{2149}$ Where consensus has not been reached on a suspected ADR, the panel will meet and discuss these individual suspected ADRs to achieve consensus. To ensure suspected ADRs were not missed, a random sample $(10 \%)$ of non-ADRs will be analysed by the panel using patient case notes. ${ }^{23}$

\section{Secondary outcomes}

Secondary outcomes include: (i) health service use; (ii) HRQOL; (iii) adherence to medication; and (iv) 
Table 1 Measures and risk factors to be collected as part of the ADR determination process

\begin{tabular}{|c|c|}
\hline Measures & Description of measures \\
\hline \multicolumn{2}{|l|}{ Medications } \\
\hline Types of medications & $\begin{array}{l}\text { ATC code, medication recently commenced (or not), self-medicated (or not), PRN } \\
\text { (or not), short course (or not), details of recently discontinued medications, over-the- } \\
\text { counter medications and allergies and sensitivities }\end{array}$ \\
\hline Number of medications & Number of medications prescribed \\
\hline Drug/drug interactions & Drug interactions assessed using Summary of Product Characteristics documents \\
\hline \multicolumn{2}{|l|}{ Disease } \\
\hline Presenting issues & Description of presenting symptoms \\
\hline Diagnosis & Diagnosis on admission (ICD-10) \\
\hline Frailty & Triage Risk Screening Tool, ${ }^{46}$ PRISMA- $7^{47}$ and FRAIL ${ }^{48}$ \\
\hline Falls & $\begin{array}{l}\text { Fallen in the past year (yes/no), fallen more than once in the past year (yes/no), } \\
\text { number of falls }\end{array}$ \\
\hline Mobility & $\begin{array}{l}\text { Use of walking aid or device when crossing a room (yes/no) or when outside (yes/no). } \\
\text { Type of walking aid or device }\end{array}$ \\
\hline Physical fitness & Self-reported physical fitness ( 0 , very bad; 10 , very good) \\
\hline Weight loss & Self-reported unintentional weight loss in the previous 6 months (yes/no) \\
\hline Vision & Encounter problems in daily life due to poor vision (yes/no) \\
\hline Hearing & Encounter problems in daily life due to poor hearing (yes/no) \\
\hline Age & Date of birth \\
\hline Gender & Male/female \\
\hline Smoking status & Current smoker, former smoker (pack year history) \\
\hline Alcohol usage & Drinks alcohol (yes/no), no of units per week \\
\hline Medical card & Yes/no \\
\hline
\end{tabular}

Medications will be coded using the WHO ATC classification system .

Blister pack is a preformed plastic packaging for medication by pharmacist.

ADR, adverse drug reaction; ATC, Anatomical Therapeutic Chemical; ICD-10, International Statistical Classification of Diseases and Related Health Problems-10th Revision.

ADR-related costs. table 2 describes the health and cost outcomes associated with ADR-related hospital admissions.

\section{Health service use}

Health service use will be measured for all patients with an ADR and control patients using patients' hospital medical records. For all patients with an ADR and control patients, the duration of their hospital stay (number of days) and their status at discharge (eg, home, long-term care, death) will be recorded based on their hospital record (table 2).

Health service use will also be measured by participant self-report using questionnaires for patients with an ADR and control patients who consent to take part in the study on medications management in older populations. Participants will be asked to complete a baseline questionnaire measuring the number of: (i) GP visits; (ii) out of hours GP services; (iii) hospital visits-A\&E 
Table 2 Health and cost outcomes and covariates associated with ADR-related hospital admissions

\begin{tabular}{|c|c|c|}
\hline Measures & Description of measures & Method of data collection \\
\hline \multicolumn{3}{|l|}{ Health service use-outcome } \\
\hline Duration of hospital stay & Number of days & Hospital medical record \\
\hline Status at discharge & Eg, home, long-term care, death & Hospital medical record \\
\hline Health services & $\begin{array}{l}\text { General practitioner visits, accident and emergency visits, } \\
\text { outpatient visits, hospitalisations, use of therapies (eg, } \\
\text { physiotherapy, occupational therapy), use of services (eg, } \\
\text { dietician, optician, chiropody, pharmacy), public health nurse, day } \\
\text { care centre and use of respite care (in the previous } 3 \text { months) }\end{array}$ & $\begin{array}{l}\text { Baseline and 3-month } \\
\text { follow-up questionnaire }\end{array}$ \\
\hline Home help & $\begin{array}{l}\text { Receipt of home help (yes/no), hours per week of paid home help } \\
\text { and unpaid home help, source of unpaid home help (eg, spouse/ } \\
\text { partner, children, etc.) }\end{array}$ & $\begin{array}{l}\text { Baseline and 3-month } \\
\text { follow-up questionnaire }\end{array}$ \\
\hline Home help activities & $\begin{array}{l}\text { Types of activities received help with in the previous month (eg, } \\
\text { walking, getting dressed, bathing, etc.) and source of help (eg, } \\
\text { home help, spouse/partner, neighbour) }\end{array}$ & $\begin{array}{l}\text { Baseline and 3-month } \\
\text { follow-up questionnaire }\end{array}$ \\
\hline \multicolumn{3}{|l|}{ HRQOL-outcome } \\
\hline EQ-5DL & $\begin{array}{l}\text { EQ-5DL is a generic measure of health for clinical and economic } \\
\text { appraisal }\end{array}$ & $\begin{array}{l}\text { Baseline and 3-month } \\
\text { follow-up questionnaire }\end{array}$ \\
\hline Self-rated health & Self-reported health compared with others of same age & $\begin{array}{l}\text { Baseline and 3-month } \\
\text { follow-up questionnaire }\end{array}$ \\
\hline Groningen Frailty Index & $\begin{array}{l}\text { Measures the loss of functions and resources in four domains: } \\
\text { physical (mobility functions, multiple health problems, physical } \\
\text { fatigue, vision, hearing), cognitive (cognitive dysfunction), social } \\
\text { (emotional isolation) and psychological (depressed mood and } \\
\text { feelings of anxiety) }\end{array}$ & $\begin{array}{l}\text { Baseline and 3-month } \\
\text { follow-up questionnaire }\end{array}$ \\
\hline Functional ability & $\begin{array}{l}\text { Falls, mobility, physical function, weight loss, hearing and vision } \\
\text { (see table } 1 \text { for details of measures) }\end{array}$ & $\begin{array}{l}\text { 3-month follow-up } \\
\text { questionnaire only (baseline } \\
\text { collected on hospital } \\
\text { admission; table 1) }\end{array}$ \\
\hline HADS & $\begin{array}{l}\text { Hospital Anxiety and Depression Scale (HADS) measures anxiety } \\
\text { and depression }\end{array}$ & $\begin{array}{l}\text { Baseline and 3-month } \\
\text { follow-up questionnaire* }\end{array}$ \\
\hline PSS-4 & Perceived Stress Scale (PSS-4) measures the perception of stress & $\begin{array}{l}\text { 3-month follow-up } \\
\text { questionnaire only* }\end{array}$ \\
\hline ICECAP-O & $\begin{array}{l}\text { The ICEpop CAPability measure for Older people (ICECAP-O) } \\
\text { measures well-being defined in a broader sense and includes } \\
\text { measures of attachment, security and independence }\end{array}$ & $\begin{array}{l}\text { 3-month follow-up } \\
\text { questionnaire only* }\end{array}$ \\
\hline \multicolumn{3}{|c|}{ Adherence to medication-outcome } \\
\hline PDC & The proportion of days covered (PDC) for each drug class & $\begin{array}{l}\text { HSE-PCRS pharmacy } \\
\text { claims data (GMS patients } \\
\text { only) }\end{array}$ \\
\hline MARS-5 & $\begin{array}{l}\text { Medication Adherence Report Scale (MARS-5) is a self-report } \\
\text { measure of intentional and unintentional adherence to medication }\end{array}$ & $\begin{array}{l}\text { Baseline and 3-month } \\
\text { follow-up questionnaire }\end{array}$ \\
\hline Medications & Number of medications and types of medication & $\begin{array}{l}\text { HSE-PCRS pharmacy } \\
\text { claims data (GMS patients } \\
\text { only) }\end{array}$ \\
\hline \multicolumn{3}{|l|}{ Cost-outcome } \\
\hline Investigations & $\begin{array}{l}\text { As required (eg, blood pressure, pulse, HbA1c, glucose, } \\
\text { international normalised ratio, creatinine, urea) }\end{array}$ & Hospital medical record \\
\hline Procedures & As required (eg, ECG, imaging, endoscopy) & Hospital medical record \\
\hline $\begin{array}{l}\text { Healthcare therapies and } \\
\text { services }\end{array}$ & $\begin{array}{l}\text { Details of therapies (eg, physiotherapy) and services (eg, } \\
\text { chiropody) provided during hospital admission }\end{array}$ & Hospital medical record \\
\hline
\end{tabular}


Table 2 Continued

\begin{tabular}{cll}
\hline Measures & Description of measures & Method of data collection \\
\hline Productivity & Had to stop or reduce amount of time working and/or attending & 3-month follow-up \\
& social activities because of health problems in the previous & questionnaire only \\
& $\begin{array}{l}\text { 3 months. Family member or friend had to stop or reduce or } \\
\text { change amount of time working because of participant's health } \\
\text { problems in the previous 3 months }\end{array}$ &
\end{tabular}

Carer allowance $\quad$ Receipt of State Carer's Allowance or Carer's Benefit to provide care for participant (yes/no) and participant's relationship with

Baseline and 3-month person receiving allowance or benefit (eg, spouse/partner, follow-up questionnaire children, not related)

Covariates

Additional sociodemographic information

\begin{tabular}{|c|c|c|}
\hline Ethnicity & Irish or other & $\begin{array}{l}\text { 3-month follow-up } \\
\text { questionnaire only }\end{array}$ \\
\hline Children & Yes/no, number of daughters and sons & $\begin{array}{l}\text { 3-month follow-up } \\
\text { questionnaire only }\end{array}$ \\
\hline Education & Level of education (eg, primary to post-graduate) & $\begin{array}{l}\text { 3-month follow-up } \\
\text { questionnaire only }\end{array}$ \\
\hline Marital status & Single, married, cohabiting, etc. & $\begin{array}{l}\text { 3-month follow-up } \\
\text { questionnaire only }\end{array}$ \\
\hline Occupational status & Employed, retired, looking after family/home, etc. & $\begin{array}{l}\text { 3-month follow-up } \\
\text { questionnaire only }\end{array}$ \\
\hline Living arrangements & With whom participant lives (eg, partner, children, live one) & $\begin{array}{l}\text { 3-month follow-up } \\
\text { questionnaire only }\end{array}$ \\
\hline Type of accommodation & $\begin{array}{l}\text { Type of accommodation participant lives in (eg, house, sheltered } \\
\text { accommodation, nursing home) }\end{array}$ & 3-month follow-up only \\
\hline
\end{tabular}

Health Insurance Health insurance status (yes/no)

Baseline questionnaire

Additional morbidity information

$\begin{array}{lll}\text { Morbidity } & \text { Diagnosed with any new medical conditions since baseline (past } & \begin{array}{l}3-\text { month follow-up } \\ \text { questionnaire only }\end{array} \\ \text { 3 months) } & \begin{array}{l}\text { RxRisk-V is an algorithm that classifies prescription drug fills into } \\ \text { chronic disease classes }\end{array} & \begin{array}{l}\text { HSE-PCRS pharmacy } \\ \text { claims data (GMS patients } \\ \text { only) }\end{array}\end{array}$

Social and personal support

LSNS-6

The Lubbens Social Network Scale (LSNS-6) is a composite

3-month follow-up

measure of family and friends networks, for use with older people, questionnaire only which asks patients how many people they have contact with and how often

$\begin{array}{lll}\text { BRS } & \begin{array}{l}\text { Brief Resilience Scale (BRS) measures participant ability to } \\ \text { recover/bounce back from stressful events }\end{array} & \begin{array}{l}\text { 3-month follow-up } \\ \text { questionnaire only* }\end{array}\end{array}$

Medication taking support and beliefs

$\begin{array}{lll}\text { ADQ } & \begin{array}{l}\text { Adherence Determinants Questionnaire (ADQ) subscale-Support/ } \\ \text { Barriers to medication taking }\end{array} & \begin{array}{l}\text { Baseline and 3-month } \\ \text { follow-up questionnaire }\end{array} \\ \text { BMQ } & \begin{array}{l}\text { Beliefs about medication questionnaire (BMQ) consists of } \\ \text { two scales assessing patients' beliefs about the necessity of }\end{array} & \begin{array}{l}\text { Baseline and 3-month } \\ \text { follow-up questionnaire* }\end{array} \\ & \begin{array}{l}\text { prescribed medication for controlling their disease and their } \\ \text { concerns about potential adverse consequences of taking it }\end{array} & \end{array}$

*will not be assessed for participants with proxy consent 
visits, hospital inpatient (including duration of stay) and outpatient visits; (iii) use of therapies (eg, physiotherapy, occupational therapy); (iv) use of services (eg, dietician, optician, hearing, pharmacy); (v) public health nurse; and (vi) use of day care centres and respite care in the previous 3 months. ${ }^{36}$ Participants will also be asked details about their use of home help, including number of hours per week (paid/unpaid), source of home help (eg, spouse/partner) and type of activities with which they receive help. Participants will be asked to answer the same questions again 3 months post-discharge (table 2).

\section{Health-related quality of life}

Participants' overall HRQOL will be assessed by the EQ-5DL and by self-reported health compared with others of the same age at baseline and 3 months post-discharge using questionnaires. ${ }^{50}$ Physical, cognitive, social and psychological functional ability will be assessed by the self-report using the Groningen Frailty Index. ${ }^{52}$ Participants will also be asked at 3 months post-discharge to self-report if they have fallen within the last 3 months, their level of mobility (use and type of walking aids) and physical fitness, any unintentional weight loss in the previous 3 months and any problems in daily life due to poor vision and/or hearing (baseline measures will be collected on hospital admission; table 1). Psychological well-being will be assessed using the Hospital Anxiety and Depression Scale at baseline and 3 months post-discharge ${ }^{53}$ Well-being in general will be measured 3 months post-discharge only and will be assessed using the ICEpop CAPability measure for Older people and the Perceived Stress Scale (table 2).$^{54}$ Psychological well-being and well-being in general will not be assessed in the abbreviated questionnaire for participants with proxy consent.

\section{Adherence to medication}

Participants' adherence to medication will be measured at baseline and 3 months post-discharge using two methodologies: (i) the proportion of days covered (PDC) from pharmacy claims data for the year previous to participants' date of admission and 3 months post-discharge for GMS patients; and (ii) the Medication Adherence Report Scale, a five-point self-assessment scale that assesses both intentional and unintentional non-adherence. ${ }^{56}$ The PDC is calculated as the sum of the days supplied for each medication divided by the number of days in the study period. ${ }^{57}{ }^{58}$ Changes in the number of medications prescribed and types of medications will be recorded between the two time periods (table 2).

\section{Costs}

Both direct and indirect costs will be estimated in order to assess the total economic burden of ADR-related hospital admissions. Direct medical costs include inpatient hospital admissions (diagnostic related groups and length of stay), investigations and procedures performed and healthcare services, for example, physiotherapy provided during hospital admission (table 2). Health service use in general and use of home help will be measured at baseline and 3 months post-discharge for patients who provide consent to take part in the study on medications management in older populations, as described above. Indirect costs include lost productivity due to absenteeism from work/ social commitments and formal and informal care from family and friends, and these will be measured by participant self-report in the follow-up questionnaire (table 2).

\section{Covariates}

A number of sociodemographic factors, as described above, will be recorded at hospital admission for all patients with an ADR and control patients. For patients who consent to take part in the study on medications management in older populations, additional sociodemographic information will be obtained including participant's ethnicity, number of children, education, marital status, occupation status and living arrangements and health insurance status. Participants' addresses will be geocoded to determine which electoral divisions (EDs) they live in. Participant deprivation will be estimated as the deprivation score of the ED in which the patient lives based on the Small Area Health Research Unit national deprivation index (table 2). ${ }^{59}$

Additional information on participant morbidity will be obtained by participant self-report in the follow-up questionnaire. Participant comorbidity will also be assessed and validated for GMS patients by applying the RxRisk-V instrument to HSE-PCRS pharmacy claims data for the year previous to the participant's date of admission and the 3 months post-discharge. The RxRisk-V is an algorithm that classifies prescription drug fills into chronic disease classes based on the WHO ATC classification system and was developed specifically for older populations (table 2). ${ }^{60}$

Participants' social support network will be measured 3 months post-discharge using the Lubbens Social Network Scale: a composite measure of family and friends networks, for use with older people, which asks patients how many people they have contact with and how often. Participant's resilience (or ability to bounce back after difficult times) will be measured 3 months post-discharge according to the Brief Resilience Scale (table 2) ${ }^{61}$ Resilience will not be measured for participants with proxy consent.

Support and barriers to medication taking and participants' beliefs about their medications will be assessed using the Adherence Determinants Questionnaire subscale and Beliefs about Medicines Questionnaire (BMQ), respectively, at baseline and 3 months post-discharge. ${ }^{62} 63$ The BMQ comprises two five-item scales assessing patients' beliefs about the necessity of prescribed medication for controlling their illness and their concerns about the potential adverse consequences of taking it (table 2). ${ }^{63}$ The beliefs and preferences of older patients regarding their medication have been shown to be associated with medication adherence. ${ }^{64} \mathrm{BMQ}$ will not be assessed for participants with proxy consent. 


\section{Data analysis}

Prevalence and characteristics of ADR-related hospital admissions Descriptive statistics will be used to summarise the results on the prevalence of ADRs, the different types of ADRs and their various classifications (eg, preventability, severity), as well as the various drug classes involved in ADRs. Descriptive statistics will include calculating and presenting rates, means (SD), medians (IQR) or percentages and frequencies, as appropriate, with $95 \%$ CIs. For proportions, the $\chi^{2}$ test will be used to compare between different types and classifications of ADRs.

\section{Risk factors associated with ADR-related hospital admissions}

The distribution of medication-related risk factors, disease-related risk factors, functional ability-related risk factors, medication adherence-related risk factors and patient-related risk factors will be compared between patients with an ADR and non-ADR-related hospital admission using relative risks (RR) and risk differences (RD). Multivariate binomial models will be used to estimate adjusted RR and RD (logit and identity link used, respectively) with $95 \%$ CIs for associations between all risk factors and ADR versus non-ADR-related hospital admissions. The risk factors for ADRs will initially be examined univariately and any at $\mathrm{p}<0.10$ will be considered in a multivariate model. The predictive discrimination of the optimum models for ADR versus non-ADR-related hospital admissions will be assessed using receiver operating characteristic curves to produce estimates of the areas under the curves (c-statistics) and 95\% CIs.

\section{Secondary health outcomes associated with ADR-related hospital admissions}

Descriptive statistics including medians (IQR), means (SD) and proportions will be used to summarise health outcomes (health service use, HRQOL, adherence), differences in health outcomes (baseline and 3-month follow-up) and covariates for ADR-related hospital admissions and non-ADR-related hospital admissions and the various types and classifications of ADR-related hospital admissions.

Log-linear and logistic regression models will be used to examine the association (unadjusted and adjusted) between ADR-related hospital admissions, the different types of ADRs and their classifications, on patient discharge outcomes and duration of hospital stay, health service use, HRQOL and medication adherence (baseline and 3-month follow-up), while controlling for covariates (eg, sociodemographics, morbidity). Covariates that are associated with individual outcomes at the $\mathrm{p}<0.10$ level will be included in multivariate models. For the final multivariate models, a $\mathrm{p}$ value $<0.05$ will be considered statistically significant.

\section{Costs associated with ADR-related hospital admissions}

Unit costs per hospital inpatient stay, investigations and invasive procedures, GP visits, paid home help and so on are available through the HSE and the National Centre for Pharmacoeconomics. Diagnosis-related group costs from the Healthcare Purchasing Office will be used to estimate hospital-based costs and costs for GP visits will be sourced from the Irish College of General Practitioners. ${ }^{65}$ These unit costs will be used to calculate total and average costs for patients with an ADR-related hospital admission and those without an ADR-related hospital admission. Costs will also be calculated per ADR classification (eg, severity, preventability).

Unit costs for indirect costs (eg, loss of productivity) will be calculated using consolidated salary scales available from the Department of Health and Central Expenditure Evaluation Unit. ${ }^{66}$ The association (unadjusted and adjusted) between ADR-related hospital admissions and indirect costs will be examined using the gamma distribution while controlling for covariates (eg, sociodemographics, morbidity). ${ }^{67}$

Analysis will be performed using Stata V.14.0 (StataCorp). Findings will be published at an aggregate level.

\section{ETHICS AND DISSEMINATION Ethical approval}

This research study was approved by Beaumont Hospital Ethics (Medical Research) Committee (Ref:16/49).

\section{Dissemination}

Dissemination will take place via peer-reviewed publications, presentations at national and international conferences, professional networks and through exchanges with relevant policy makers and healthcare practitioners, patients, family members and service users.

\section{STRENGTHS AND LIMITATIONS}

This study will provide detailed information on the prevalence and characterisation of ADRs in a large older population. There have been no long-term follow-up studies of older patients with ADR-related hospital admissions and this study will assess a range of health and cost outcomes. This study has a number of limitations. The determination of ADR prevalence includes a multifaceted review of each suspected ADR including clinical judgement and chart review, the application of a number of decision aids and validated algorithms as well as independent review by an expert panel using a consensus method. However, ADR determination in older populations is challenging and there is a risk of misclassification, given that older people often have several comorbidities and disabilities and are prescribed numerous medications.

A number of measures in the study are based on patient self-report and patient recall may be inaccurate. Where feasible, information on health outcomes will be taken from other sources (eg, HSE-PCRS pharmacy claims database for adherence). The application of all of the STOPP and START criteria to patients with an ADR-related hospital admission and control patients will not be possible, due to a lack of information on the specific 
duration of patient's medication usage prior to hospital admission. However, these criteria will be applicable for GMS patients, who provide consent, derived from their HSE-PCRS pharmacy claims data. Diagnostic and laboratory data will also be available to support the application of these criteria, which is generally not available in the community setting.

The study has estimated a $50 \%$ response rate for patients with an ADR-related hospital admission and control patients consenting to take part in a prospective cohort study investigating medication management in older populations. In order for this study to accurately measure ADR-related health and cost outcomes in older populations and reduce research bias, the study population needs to include participants who may not have the capacity to give informed consent due to cognitive impairments or severity of illness. Previous research on the hospitalisation of older people in Ireland has indicated that the prevalence of dementia is $25 \%$ in those admitted to hospital. ${ }^{68}$ Participants will be offered the possibility of completing the questionnaire measures in person or by phone and, where feasible, a proxy (next of kin, person closest to the patient) will be sought to provide assent to take part in the study. However, it is likely that a number of patients will not have the capacity to complete the questionnaire measures and the proposed response rate is overestimated and the analyses for some associations of interest will be underpowered. While we aim to adjust for a number of covariates, it is also possible that there may be other unknown or unmeasured covariates.

Due to the difficulty in determining causality of ADRs immediately, it is possible that patients with a suspected $\mathrm{ADR}$, as determined by the research team and are invited to take part in the prospective cohort study, will be determined not to have a 'true ADR' after expert panel review (figure 1). However, the expected numbers are likely to be small and, therefore, unlikely to impact on the overall study size.

\section{CONCLUSIONS}

This study will provide important estimates of the occurrence of ADR-related hospital admissions in older populations, the risk factors associated with ADRs and an assessment of the health and cost outcomes associated with ADR-related hospital admissions. This study will provide information which will be of benefit to the public, healthcare professionals and policy makers and will inform service planning, methods of reducing future ADRs and improving medication management in older populations.

Contributors $\mathrm{CaC}, \mathrm{CC}$, DW and $\mathrm{KB}$ conceived and designed the study. CaC drafted the manuscript. $\mathrm{CC}, \mathrm{CB}, \mathrm{CW}, \mathrm{AH}$, DW and $\mathrm{KB}$ provided expertise in their respective fields, all critically reviewed the manuscript and approved the final version of the manuscript for submission.

Funding $\mathrm{CaC}, \mathrm{CB}$ and $\mathrm{CW}$ are supported by the Health Research Board Ireland (RL-2015-1579). CC is supported by the RCSI StAR MD programme.

Competing interests None declared.
Ethics approval Beaumont Hospital

Provenance and peer review Not commissioned; peer reviewed.

Open Access This is an Open Access article distributed in accordance with the Creative Commons Attribution Non Commercial (CC BY-NC 4.0) license, which permits others to distribute, remix, adapt, build upon this work non-commercially, and license their derivative works on different terms, provided the original work is properly cited and the use is non-commercial. See: http://creativecommons.org/ licenses/by-nc/4.0/

(c) Article author(s) (or their employer(s) unless otherwise stated in the text of the article) 2017. All rights reserved. No commercial use is permitted unless otherwise expressly granted.

\section{REFERENCES}

1. Edwards IR, Aronson JK. Adverse drug reactions: definitions, diagnosis, and management. Lancet 2000;356:1255-9.

2. Green CF, Mottram DR, Rowe PH, et al. Adverse drug reactions as a cause of admission to an acute medical assessment unit: a pilot study. J Clin Pharm Ther 2000;25:355-61.

3. Davies EC, Green CF, Mottram DR, et al. Adverse drug reactions in hospitals: a narrative review. Curr Drug Saf 2007;2:79-87.

4. Pirmohamed M, James S, Meakin S, et al. Adverse drug reactions as cause of admission to hospital: prospective analysis of 18820 patients. BMJ 2004;329:15-19.

5. Wester K, Jönsson AK, Spigset $\mathrm{O}$, et al. Incidence of fatal adverse drug reactions: a population based study. Br J Clin Pharmacol 2008;65:573-9.

6. Moore N, Lecointre D, Noblet C, et al. Frequency and cost of serious adverse drug reactions in a department of general medicine. $\mathrm{Br} J$ Clin Pharmacol 1998;45:301-8.

7. Lehnert T, Heider D, Leicht $\mathrm{H}$, et al. Review: health care utilization and costs of elderly persons with multiple chronic conditions. Med Care Res Rev 2011;68:387-420.

8. Shi S, Klotz U. Age-related changes in pharmacokinetics. Curr Drug Metab 2011;12:601-10.

9. Franceschi M, Scarcelli C, Niro V, et al. Prevalence, clinical features and avoidability of adverse drug reactions as cause of admission to a geriatric unit: a prospective study of 1756 patients. Drug Saf 2008;31:545-56.

10. Kongkaew C, Noyce PR, Ashcroft DM. Hospital admissions associated with adverse drug reactions: a systematic review of prospective observational studies. Ann Pharmacother 2008;42:1017-25.

11. Alhawassi TM, Krass I, Bajorek BV, et al. A systematic review of the prevalence and risk factors for adverse drug reactions in the elderly in the acute care setting. Clin Interv Aging 2014;9:2079-86.

12. De Paepe P, Petrovic M, Outtier L, et al. Drug interactions and adverse drug reactions in the older patients admitted to the emergency department. Acta Clin Belg 2013;68:15-21.

13. Davies EA, O'Mahony MS. Adverse drug reactions in special populations - the elderly. Br J Clin Pharmacol 2015;80:796-807.

14. Patel NS, Patel TK, Patel PB, et al. Hospitalizations due to preventable adverse reactions - a systematic review. Eur J Clin Pharmacol 2017;73:385-98.

15. Walsh D, Lavan A, Cushen AM, et al. Adverse drug reactions as a cause of admission to a Dublin-based university teaching hospital. Ir J Med Sci 2015;184:441-7.

16. Ahern F, Sahm LJ, Lynch D, et al. Determining the frequency and preventability of adverse drug reaction-related admissions to an Irish university hospital: a cross-sectional study. Emerg Med J 2014;31:24-9.

17. Sari AB, Sheldon TA, Cracknell A, et al. Sensitivity of routine system for reporting patient safety incidents in an NHS hospital: retrospective patient case note review. BMJ 2007;334:79.

18. Waller P, Shaw M, Ho D, et al. Hospital admissions for 'drug-induced' disorders in England: a study using the Hospital Episodes Statistics (HES) database. Br J Clin Pharmacol 2005;59:213-9.

19. Hazell L, Shakir SA. Under-reporting of adverse drug reactions: a systematic review. Drug Saf 2006;29:385-96.

20. Williams DJ, Olsen S, Crichton W, et al. Detection of adverse events in a scottish hospital using a consensus-based methodology. Scott Med J 2008;53:26-30.

21. Hajjar ER, Hanlon JT, Artz MB, et al. Adverse drug reaction risk factors in older outpatients. Am J Geriatr Pharmacother 2003;1:82-9.

22. Cahir C, Bennett K, Teljeur C, et al. Potentially inappropriate prescribing and adverse health outcomes in community dwelling older patients. Br J Clin Pharmacol 2014;77:201-10. 
23. Hamilton H, Gallagher P, Ryan C, et al. Potentially inappropriate medications defined by STOPP criteria and the risk of adverse drug events in older hospitalized patients. Arch Intern Med 2011;171:1013-9.

24. Field TS, Mazor KM, Briesacher B, et al. Adverse drug events resulting from patient errors in older adults. J Am Geriatr Soc 2007;55:271-6.

25. Onder G, Petrovic M, Tangiisuran B, et al. Development and validation of a score to assess risk of adverse drug reactions among in-hospital patients 65 years or older: the GerontoNet ADR risk score. Arch Intern Med 2010;170:1142-8.

26. Tangiisuran B, Scutt G, Stevenson J, et al. Development and validation of a risk model for predicting adverse drug reactions in older people during hospital stay: Brighton Adverse Drug Reactions rlsk (BADRI) model. PLoS One 2014;9:e111254.

27. Hohl CM, Nosyk B, Kuramoto L, et al. Outcomes of emergency department patients presenting with adverse drug events. Ann Emerg Med 2011;58:270-9.

28. Bond CA, Raehl CL. Adverse drug reactions in United States hospitals. Pharmacotherapy 2006;26:601-8.

29. Wu C, Bell CM, Wodchis WP. Incidence and economic burden of adverse drug reactions among elderly patients in Ontario emergency departments: a retrospective study. Drug Saf 2012;35:769-81.

30. Hopf $Y$, Watson M, Williams D. Adverse-drug-reaction related admissions to a hospital in Scotland. Pharm World Sci 2008;30:854-62.

31. Hamilton HJ, Gallagher PF, O'Mahony D. Inappropriate prescribing and adverse drug events in older people. BMC Geriatr 2009;9:5.

32. Morimoto T, Gandhi TK, Seger AC, et al. Adverse drug events and medication errors: detection and classification methods. Qual Saf Health Care 2004;13:306-14.

33. Rawlins M, Thompson J. Mechanisms of adverse drug reactions. Davies DM ed Textbook of adverse drug reactions. Oxford: Oxford University Press, 1991

34. Naranjo CA, Busto U, Sellers EM, et al. A method for estimating the probability of adverse drug reactions. Clin Pharmacol Ther 1981;30:239-45.

35. World Health Organisation. The WHO adverse reaction terminologyWHO-ART. The Uppsala Monitoring Center 2005.

36. Gallagher RM, Kirkham JJ, Mason JR, et al. Development and inter-rater reliability of the liverpool adverse drug reaction causality assessment tool. PLoS One 2011;6:e28096.

37. Hallas J, Harvald B, Gram LF, et al. Drug related hospital admissions: the role of definitions and intensity of data collection, and the possibility of prevention. J Intern Med 1990;228:83-90.

38. Hartwig S, Siegel J, Schneider P. Preventability and severity assessment in reporting adverse drug reactions. Am Journal Health Syst Pharm 1992;49:2229-32.

39. Health Services Executive. Primary care reimbursement services: statistical analysis of claims and payments. Dublin: Ireland, 2010.

40. Naughton C, Bennett K, Feely J. Prevalence of chronic disease in the elderly based on a national pharmacy claims database. Age Ageing 2006;35:633-6.

41. WHO anatomical therapeutic chemical (ATC) classification. Oslo, Norway: WHO Collaborating Centre.

42. O'Mahony D, O'Sullivan D, Byrne S, et al. STOPP/START criteria for potentially inappropriate prescribing in older people: version 2. Age Ageing 2015;44:213-8.

43. Charlson M, Szatrowski TP, Peterson J, et al. Validation of a combined comorbidity index. J Clin Epidemiol 1994;47:1245-51.

44. De J, Wand APF, Smerdely PI, et al. Validating the 4A's test in screening for delirium in a culturally diverse geriatric inpatient population. Int J Geriatr Psychiatry 2016;43.

45. Clegg A, Rogers L, Young J. Diagnostic test accuracy of simple instruments for identifying frailty in community-dwelling older people: a systematic review. Age Ageing 2015;44:148-52.
46. Fan J, Worster A, Fernandes CMB. Predictive validity of the Triage Risk Screening Tool for elderly patients in a Canadian emergency department. Am J Emerg Med 2006;24:540-4.

47. Hebert R, Raiche M, Dubois M-F, et al. Impact of PRISMA, a coordination-type integrated service delivery system for frail older people in Quebec (Canada): a quasi-experimental study. J Gerontol B Psychol Sci Soc Sci 2010;65B:107-18.

48. van Kan GA, Rolland YM, Morley JE, et al. Frailty: toward a clinical definition. J Am Med Dir Assoc 2008;9:71-2.

49. Ab Latif R, Mohamed R, Dahlan A, et al. Using Delphi technique: making sense of consensus in concept mapping structure and multiple choice questions (MCQ). Educ Med J 2016;8.

50. Oppe M, Devlin NJ, van Hout B, et al. A program of methodological research to arrive at the new international EQ-5D-5L valuation protocol. Value in Health 2014;17:445-53.

51. Saliba D, Elliott M, Rubenstein LZ, et al. The vulnerable elders survey: a tool for identifying vulnerable older people in the community. J Am Geriatr Soc 2001;49:1691-9.

52. Peters LL, Boter H, Buskens E, et al. Measurement properties of the groningen frailty indicator in home-dwelling and institutionalized elderly people. J Am Med Dir Assoc 2012:13:546-51.

53. Zigmond AS, Snaith RP. The Hospital Anxiety and Depression Scale. Acta Psychiatr Scand 1983;67:361-70.

54. Flynn TN, Chan P, Coast J, et al. Assessing quality of life among British older people using the ICEPOP CAPability (ICECAP-O) measure. Appl Health Econ Health Policy 2011;9:317-29.

55. Cohen S, Kamarck T, Mermelstein R. A global measure of perceived stress. J Health Soc Behav 1983;24:385-96.

56. Horne R, Weinman J, Hankins M. The beliefs about medicines questionnaire: the development and evaluation of a new method for assessing the cognitive representation of medication. Psychol Health 1999:14:1-24.

57. Steiner JF, Prochazka AV. The assessment of refill compliance using pharmacy records: methods, validity, and applications. J Clin Epidemiol 1997;50:105-16.

58. Choudhry NK, Shrank WH, Levin RL, et al. Measuring concurrent adherence to multiple related medications. Am J Manag Care 2009;15:457-64.

59. Kelly A, Teljeur CT. The national deprivation index for health \& health services research. Dublin: SAHRU Technical Report, 2007.

60. Sloan KL, Sales AE, Liu CF, et al. Construction and characteristics of the RxRisk-V: a VA-adapted pharmacy-based case-mix instrument. Med Care 2003;41:761-74.

61. Smith BW, Dalen J, Wiggins $\mathrm{K}$, et al. The brief resilience scale: assessing the ability to bounce back. Int J Behav Med 2008;15:194-200.

62. DiMatteo MR, Hays RD, Gritz ER, et al. Patient adherence to cancer control regimens: scale development and initial validation. Psychol Assess 1993;5:102-12.

63. Horne R, Weinman J. Patients' beliefs about prescribed medicines and their role in adherence to treatment in chronic physical illness. $J$ Psychosom Res 1999;47:555-67.

64. Phatak HM, Thomas J. Relationships between beliefs about medications and nonadherence to prescribed chronic medications. Ann Pharma 2006;40:1737-42.

65. Guidelines for the Economic evaluation of Health Technologies in Ireland. Dublin, Ireland: Health Information and Quality Authority, 2014.

66. 2013. Central Expenditure evaluation unit. the Public spending code: calculation of staff costs. Presented at Department of Public Expenditure and Reform, Dublin, Ireland. http://publicspendingcode. per.gov.ie/e-01-calculation-of-staff-costs

67. Nixon RM, Thompson SG. Parametric modelling of cost data in medical studies. Stat Med 2004;23:1311-31.

68. Timmons S, Manning E, Barrett A, et al. Dementia in older people admitted to hospital: a regional multi-hospital observational study of prevalence, associations and case recognition. Age Ageing 2015;44:993-9. 